\title{
Forgetting the Lessons of History
}

\author{
Barbara A. Wanchisen \\ Baldwin-Wallace College
}

\begin{abstract}
While a great deal of behavior analytic research has focussed on studying current contingencies, the amount of work done in the area of conditioning history is spotty, at best. Weiner $(1964,1969)$ conducted history research with human subjects, but little has followed in either the human or the nonhuman literature. Some direction can also be found in the literature studying the effects of conditioning on drug effects (e.g., Barrett, 1977; Urbain, Poling, Millam, \& Thompson, 1978). However, "behavioral history" or "conditioning history" has not been a fully-developed area within behavior analysis. It is suggested that empirical work on history effects might have implications for (a) better understanding humannonhuman behavioral differences and similarities, (b) clinical applications, especially where clients are resistant to behavioral change, and (c) theoretical assumptions in behavior analysis in relation to both basic and applied concerns.

Key words: conditioning history, behavioral persistence, reinforcement schedules, continuity theory, behavior analytic theory, human-nonhuman differences, clinical applications, behavioral variability
\end{abstract}

Skinner (1953) stated that the way we will be able to explain an organism's present behavior is through studying variables "in its immediate environment and in its environmental history" (p. 31). The focus of behavior analytic research with nonhumans has been primarily on the former, with slight attention to the latter. History effects have been mentioned in relation to human behavior (Michael, 1980; Shimoff, 1986), usually as an uncontrollable source of variability, but little empirical work has been done. Additionally, these passing references are made regarding extra-laboratory history and the assumption has been that this history can account for individual differences across human subjects.

In the recent anniversary issue of the Journal of the Experimental Analysis of Behavior, Azrin (1987), in an attempt to describe the prevailing views of behavior analysts years ago, stated, "lower animals were used by most investigators in large part to control for unknown histories" (p. 481). This view is still basically

I would like to thank Thomas A. Tatham for his insightful suggestions on this manuscript (and for providing a clever title). Many of the points made in this paper are a direct result of stimulating discussions that he and I have had over the last several years. Reprint requests should be addressed to the author at the following address: Department of Psychology, Baldwin-Wallace College, Berea, OH 44017. intact today with those engaging in nonhuman research. It is obvious that a great deal of valuable work has been done using these practices, and, while much work still needs to be done with naive nonhuman animals (cf. Zeiler, 1985), an added dimension would be to include studies where the past history is manipulated before the subject receives the planned contingency.

\section{WHAT IS "HISTORY"?}

It is necessary to develop a definition of what "history" actually means, but this is not as easy as it sounds. For example, while it is assumed that nonhumans are naive before serving as subjects in an experiment, they certainly have had numerous experiences before arriving at the laboratory. That is, being raised among siblings and then shipped to a new location where they are typically housed individually can be considered a kind of history. Perhaps (unintentional) differences in raising nonhumans can account for some of the variability in their later behavior in the operant chamber. If this is "history," maybe it can not be included in the present definition because it would be difficult to control (unless one raised one's own rats or pigeons, but then again, they would need to be videotaped twenty-four hours per day to capture all of the contingencies to which the subject was 
exposed). This might be called "extralaboratory" or "extra-experimental" history in that it is unrelated to directly manipulated experimental contingencies.

As for humans, particularly adult humans, extra-laboratory history is extensive. Studying those elements of history would be retrospective and not in keeping with a behavioral analysis. It seems, then, reasonable to limit (for now) what we mean by "history" to include only "experimental history," that is, the exposure to particular operant or respondent contingencies carefully controlled in a laboratory setting, before the desired "test phase" is introduced. Perhaps, for those of us in the behavior analytic community, our first focus could be on schedules of reinforcement and how schedule history may affect behavior on subsequent schedules of reinforcement.

Presently, quite a bit is known about schedule effects, for example, what behavioral patterns can be expected from each schedule using experimentally-naive subjects, and, in some cases, patterns of choice given the presence of more than one schedule. Schedule effects are considered so well-defined that they are often used as a baseline by which the efficacy of other variables can be tested. This is clearly seen in the area of psychopharmacology (see Leander \& McMillan, 1976) and, interestingly, it is within this field that some pointed work on schedule history has been done.

Barrett (1977) exposed two monkeys to schedules involving both shock postponement and shock presentation while two other monkeys received an appetitive schedule. He then exposed all four to a fixed-interval (FI), providing food reinforcement, until responding became stable. He introduced a punishment contingency, obtained stability on that, and finally introduced d-amphetamine sulphate. It was with this drug administration that the effects of the shock history were seen: The shock-history subjects obtained much higher response rates than did the other two subjects. Barrett demonstrated that a drug's effects could be profoundly modulated by conditioning history. In subsequent work with pi- geons, Barrett and Stanley (1980) showed that, given an ascending and descending series of multiple FI fixed-ratio (FR) schedules with food reinforcement, ethanol's effects were different at various points in the series. They, too, suggested that conditioning history was the key determinant in the behavioral patterns seen under the influence of the drug.

More recently, Egli and Thompson (1989) turned the emphasis from noting how differently subjects with different histories behave in a subsequent drug condition to suggesting that drug administration can be used to uncover information about the subject's experimental history. They pointed out that as a subject is exposed to a number of conditions and brought to stability, history effects may seem to be eliminated. Egli and Thompson stated, "under steady state conditions, however, some variables that operated previously to shape current behavior may be latent [italics added]" (pp. 141-142). Using Alternative FR FI schedules with pigeons serving as subjects, they demonstrated that methadone (and suggested that possibly other drugs) "may reveal the presence of latent indirect variables by unmasking the presence of those sources of behavioral control acquired via prior exposure to differing reinforcement requirements" (p. 153). Studies along these lines may one day provide a means by which to identify the kinds of prior contingencies a subject received before being exposed to a current set of contingencies. Being able to know what happened in an organism's past (that which Egli \& Thompson call "latent") is an exciting possibility.

Along these lines, using d-amphetamine, Urbain, Poling, Millam, and Thompson (1978) showed that manipulating schedule history with an FR or an inter-response-time-greater-than-t (IRT $>$ t) can also have a decided effect upon responding under a subsequent FI schedule. They found that rats in an FR-history group produced much higher rates of responding than the IRT $>t$ rats. This effect reportedly lasted to the end of the experiment, or 93 sessions. They pointed out the similarity of their findings to the 
human studies conducted by Weiner $(1964,1969)$ and commented on how a particular history can affect both human and nonhuman FI performance in the same ways.

Some nonhuman studies have described history effects without drug manipulations. In studying the effects of deprivation on the extinction of a multiple variable-interval (mult VI) contingency, Gollub and Urban (1958) used two pigeons who were naive and two who were experienced before the experiment began. While this choice of subjects was not reportedly aimed at studying history effects, they found that the experienced birds responded more during extinction than the naive birds, and attributed this discrepancy to prior history.

In a study that directly manipulated experimental history, Keller and Gollub (i977) exposed pigeons to a number of different concurrent VIs and found consistent evidence of undermatching on those schedules as opposed to birds who did not receive this substantial amount of history. They made the argument that their experiment could shed light on why researchers have reported discrepant findings in studies analyzing the matching law. This was a clever study on experimental history, but a possible confounding factor may be the fact that, according to the authors, at least half of the birds "had extensive prior training" (p. 147). At that time (and even now), reporting on the specifics of a nonhuman's experimental history was not required (and perhaps this had no effect on the experiment they reported) but it would be helpful in the future if authors were required to provide detailed accounts of experimental history.

Alleman and Zeiler (1974) showed, with pigeons, that a history of an FR schedule was the key determinant in subsequent rates of responding under various fixed-time (FT) schedules. Specifically, the FT response patterns showed scalloping, a pattern more usually seen in the FI. More recently, Wanchisen, Tatham, and Mooney (1989) presented experimentally-naive rats with a history of a variable-ratio (VR) schedule prior to an FI exposure, with control subjects receiving the FI alone. They found that the experimental rats produced high- and/or low-rate patterns on the FI component whereas the controls more typically emitted scallops and/or break-run patterns.

Studies with human subjects (Weiner, $1964,1969)$ have also shown evidence of experimental history effects. Weiner reported that a history of a differential reinforcement of low-rate schedule, i.e., a DRL, will produce low-rate FI patterns, whereas a history of a high-rate schedule, i.e., an FR, will produce high-rate FI patterns. Weiner (1970) called this area "human behavioral persistence" and identified a relationship between the phenomena he was interested in studying and the Newtonian concept of momentum. Weiner attributed this human behavioral persistence to (a) a particular conditioning history inside the laboratory and (b) the current schedule being presented to the subject that reinforces this persistence. While it may be true that his subjects clearly continued to emit the former behavioral pattern, hence the term "persistence" was used, it should be noted that history effects can be more subtle over time. It may be that his subjects received too few sessions to determine whether the history would cause persistence beyond the number of FI sessions reported, or if the effects of history would eventually cause other behavioral patterns. As noted earlier, Egli and Thompson stated that history effects can be masked over time once steady state behavior is achieved on a current contingency.

Another avenue involving history effects comes from the conditioned suppression (Estes \& Skinner, 1941) literature. The standard procedure involves obtaining a steady state of lever pressing for food reinforcement, followed by the presentation of unavoidable signalled shock. In time, the signal will suppress lever pressing until the signal is terminated. Sidman, Herrnstein, and Conrad (1957) changed the experimental history from positive reinforcement to a shockavoidance procedure where lever pressing could postpone the next shock (the 
Sidman avoidance procedure). This experiment showed the opposite result seen in Estes and Skinner; that is, responding was greatly increased instead of being suppressed. Next they discontinued the avoidance contingency, leaving only the unavoidable signalled shock, and found that the subjects responded vigorously throughout presentation of the signal. Interestingly, Herrnstein and Sidman (1958) extended this by exposing monkeys to the Estes-Skinner conditioned suppression procedure followed by Sidman avoidance and then returned to conditioned suppression. In the final phase of conditioned suppression, they found increased responding on the food-reinforcement schedule during the signal just as Sidman et al. found without food presentation. These studies suggested that exposure to the Sidman avoidance procedure produced an increase in responding in subsequent signalled-shock conditions, with or without food present. Here, then, we see that negative reinforcement can have a decided effect on subsequent behavior.

While this overview of some of the relevant literature is certainly not exhaustive, it may be suggestive of the types of research that can be pursued to better understand the effects of experimental history on present behavior. I have considered operant behavior, primarily the effects of schedule history and have not included respondent conditioning nor areas like "learned helplessness" where the history involves presentation of a noncontingent relationship. That is not to say that these are not important areas of concern, but that this paper is limited to presenting one facet of history to possibly spark interest in the topic, with the suggestion that other areas be approached as well.

\section{Implications of Studying History Effects}

It would be valuable for the behavior analytic community to focus efforts upon systematically studying history effects. While the actual result of such an effort is unknowable, there are at least three general ways history research could have an impact.

1. Work on history effects may lend insight into human-nonhuman differences and similarities. There has been a growing faction within the behavior analytic community that entertains the notion of behavioral noncontinuity between humans and nonhumans (Hayes, 1987a, 1987b). The evidence for such a position is mostly attributed to the presence of language in humans (Hayes, 1987b; Lowe, Beasty, \& Bentall, 1983). Those rejecting this assumption and siding with traditional evolutionary theory (see Perone, Galizio, \& Baron, 1988) suggest that there are enough procedural differences between how humans are studied compared to nonhumans that to abandon continuity theory at this stage is unfounded and unwise. In sympathy with this latter view, many have pointed out that another glaring difference in studying humans and nonhumans is that humans have a much greater history of reinforcement before entering any laboratory experiment (Perone et al., 1988; Shimoff, 1986; Wanchisen et al., 1989; Weiner, 1983). In contrast, nonhumans typically are experimentally-naive. Comparisons are made anyway in the empirical research, with a focus on how differently the humans behave (for an interesting discussion, see Weiner, 1983). It is likely that we may never know why humans behave so differently, as prevailing ethics would not allow careful manipulation of humans' reinforcement histories as it would with nonhumans. That is not to say that history work with humans is unfeasible, just that it will have greater limitations.

One avenue would be to first carefully study both humans and nonhumans, using procedures that are as similar as possible. Next, one might manipulate variables to determine how to produce the same behavioral patterns across species, such that cumulative records, IRT distributions, and the like are indistinguishable. For example, consider the similarities of Urbain et al.'s (1978) and Wanchisen et al.'s (1989) studies using nonhuman subjects with Weiner's (1964, 1969) human studies. Both Urbain et al. 
and Wanchisen et al. point out that after a particular schedule history, the subsequent FI patterns of nonhumans were strikingly similar to human FI performance. Therefore, if a particular history can be "the great equalizer," then perhaps one way to better compare human and nonhuman behavior on schedules of reinforcement is through providing similar experimental histories before presenting the targeted contingency. Any human-nonhuman discrepancies noted on the targeted contingency, then, could be explored more fully instead of making casual attributions to the humans' extralaboratory histories. While it may not turn out to be so simple (perhaps, for example, the humans' extra-laboratory histories continue to pose difficulties) this, at least, is a start to an empirical investigation.

Of course, one must be cautious in ascribing history effects as the sole or primary cause of human/nonhuman differences. While the data are suggestive of history as an important factor, procedural differences need further investigation as well, e.g., differences in experimental equipment and the use of primary versus secondary reinforcers. It is probably the case that some interaction of several factors will explain the behavioral differences between humans and nonhumans.

2. Studying history effects may have clinical implications. Cullen (1988) argued that further experimentation with nonhumans will likely yield no useful application for behavioral clinicians. Perhaps this view is not generally held by all clinicians, but studies in history effects could ignite new interest in that community. Clinicians surely are concerned with the difficulty in changing clients' well-learned behavioral patterns, and sometimes they attribute this difficulty to the schedules of reinforcement the client has received in the past (see Barlow \& Hersen, 1984). Adding to this the amount of time the person was exposed to certain types of reinforcement contingencies and the degree to which reinforcement changed may also provide important information (see Deitz, Fredrick, Quinn, \& Brasher, 1986).
Nonbehavioral and some behavioral clinicians may attribute present maladaptive behavior to traumatic events in the client's past (and this may be a valid assumption) but the necessary research in this area needs to be done to confirm or reject how much of an effect earlier experiences may have on present behavior. Work could be done with both humans and nonhumans, basic as well as applied, with an emphasis on nonhuman research given the possible ethical implications.

Another route to investigate would be to identify contingencies that return the organism to "normal" behavioral patterns. If history is shown to permanently affect present behavior, then perhaps we can come to predict the "best" and "worst" case for treatment efficacy. Weiner (1969), however, suggested that a particular history minimizes inter-subject variability with humans, thus reducing extra-laboratory, individual history effects. Perhaps this could be applied to clinical work, e.g., first providing a client with a particular history of reinforcement and then introducing the desired contingency. In that way, the actual treatment could be started after eliminating some possible sources of variability and may make for a more effective treatment. In any event, no matter what the orientation of the clinician, data on how history affects present behavior could be of help in modifying present behaviors.

3. Adjustments in behavior analytic theory and methodology may need to be made to account for new avenues of research. While it is true that Skinner (1953) suggested that history of reinforcement is a powerful determinant of present behavior, "lab lore" seems to suggest that this holds primarily for human behavior. Most of us have believed that nonhumans are sensitive to contingency changes with history having little or no effect upon the power of the present contingency. In fact, for some reason, this is held to be particularly true with pigeons-it is a common practice to use the same pigeons for years and/or to swap pigeons with another laboratory. Further, if some history effects are transitory, perhaps study- 
ing transitional behavior patterns, in addition to steady-state ones, will provide an additional data base of interest.

The fact that history effects may be irreversible in some cases would also pose some difficulties with behavior analytic theory. The basic A-B-A design may not be appropriate for some history designs as the return to baseline may not recapture the original behavior in all cases. For example, Wanchisen et al. (1989) did not see the return of the FI scallop after a VR history, thus suggesting that this type of research may be best couched in terms of between-subject designs. This is not to say that single-subject designs are not feasible, in fact they should be actively pursued, just that there may be cases where one is constrained to use betweensubject, larger $N$, designs to answer a particular research question.

\section{CONCLUSIONS}

The complexity of defining, and then empirically investigating, the effects that experimental history has on present behavior is a challenge to those of us engaged in the experimental analysis of behavior. Offered here is some direction in the area of studying operant history, primarily as it relates to schedules of reinforcement. However, an expansion of what "history" should encompass followed by division into manageable areas of research is also needed. Input from a variety of behavior analysts would be beneficial to attaining this goal. Once done, perhaps researchers in other areas of psychology could apply our template to their disciplines as well.

While the first two implications stated in this paper may or may not be controversial, we must be willing to wrestle with the third, that is how behavior analytic theory and research methodology may be expanded or modified as a function of conducting research in the area of history effects. I hope that discussions on this will center on the importance of how to answer the questions, instead of strict adherence to the paradigm as it now stands. But the first step is to identify the need to intensively conduct research in the area of experimental history, an avenue of exploration that behavior analysis is particularly well-suited to address.

\section{REFERENCES}

Alleman, H. D., \& Zeiler, M. D. (1974). Patterning with fixed-time schedules of response-independent reinforcement. Journal of the Experimental Analysis of Behavior, 22, 135-141.

Azrin, N. H. (1987). Behavior in the beginning. Journal of the Experimental Analysis of Behavior, $48,480-481$.

Barlow, D. H., \& Hersen, M. (1984). Single case experimental designs: Strategies for studying behavior change (2nd ed.). New York: Pergamon.

Barrett, J. E. (1977). Behavioral history as a determinant of the effects of d-amphetamine on punished behavior. Science, 198, 67-69.

Barrett, J. E., \& Stanley, J. A. (1980). Effects of ethanol on multiple fixed-interval fixed-ratio schedule performance: Dynamic interactions at different fixed-ratio values. Journal of the $E x$ perimental Analysis of Behavior, 34, 185-198.

Cullen, C. (1988). Applied behavior analysis: Contemporary and prospective agenda. In $\mathbf{G}$. Davey \& C. Cullen (Eds.), Human operant conditioning and behavior modification (pp. 15-25). Chichester, England: John Wiley \& Sons.

Deitz, S. M., Fredrick, L. D., Quinn, P. C., \& Brasher, L. D. (1986). Comparing the effects of two correction procedures on human acquisition of sequential behavior patterns. Journal of the $E x$ perimental Analysis of Behavior, 46, 1-14.

Egli, M., \& Thompson, T. (1989). Effects of methadone on alternative fixed-ratio fixed-interval performance: Latent influences on schedule-controlled responding. Journal of the Experimental Analysis of Behavior, 52, 141-153.

Estes, W. K., \& Skinner, B. F. (1941). Some quantitative properties of anxiety. Journal of Experimental Psychology, 29, 390-400.

Gollub, L. R., \& Urban, J. T. (1958). The accentuation of a rate difference during extinction. Journal of the Experimental Analysis of Behavior, 1, 365-369.

Hayes, S. C. (1987a). Upward and downward continuity: It's time to change our strategic assumptions. Behavior Analysis, 22(1), 3-6.

Hayes, S. C. (1987b). Language and the incompatibility of evolutionary and psychological continuity. Behavior Analysis, 22(2), 49-54.

Herrnstein, R. J., \& Sidman, M. (1958). Avoidance conditioning as a factor in the effects of unavoidable shocks on food-reinforced behavior. Journal of Comparative and Physiological Psychology, 51, 380-385.

Keller, J. V., \& Gollub, L. R. (1977). Duration and rate of reinforcement as determinants of concurrent responding. Journal of the Experimental Analysis of Behavior, 28, 145-153.

Leander, J. D., \& McMillan, D. E. (1976). Effects of drugs on schedule-controlled behavior. In $\mathrm{S}$. D. Glick \& J. D. Goldfarb (Eds.), Behavioral pharmacology (pp. 85-139). St. Louis: Mosby. 
Lowe, C. F., Beasty, A., \& Bentall, R. P. (1983). The role of verbal behavior in human learning: Infant performance on fixed-interval schedules. Journal of the Experimental Analysis of Behavior, 39, 157-164.

Michael, J. L. (1980). Flight from behavior analysis. The Behavior Analyst, 3(2), 1-22.

Perone, M., Galizio, M., \& Baron, A. (1988). The relevance of animal-based principles in the laboratory study of human operant conditioning. In G. Davey \& C. Cullen (Eds.), Human operant conditioning and behavior modification (pp. 5985). Chichester, England: Wiley.

Shimoff, E. (1986). Post-session verbal reports and the experimental analysis of behavior. Analysis of Verbal Behavior, 4, 19-22.

Sidman, M., Herrnstein, R. J., \& Conrad, D. G. (1957). Maintenance of avoidance behavior by unavoidable shocks. Journal of Comparative and Physiological Psychology, 50, 553-557.

Skinner, B. F. (1953). Science and human behavior. New York: Macmillan.

Urbain, C., Poling, A., Millam, J., \& Thompson, T. (1978). d-Amphetamine and fixed-interval performance: Effects of operant history. Journal of the Experimental Analysis of Behavior, 29, 385392.

Wanchisen, B. A., Tatham, T. A., \& Mooney, S. E. (1989). Variable-ratio conditioning history produces high- and low-rate fixed-interval performance in rats. Journal of the Experimental Analysis of Behavior, 52, 167-179.

Weiner, H. (1964). Conditioning history and human fixed-interval performance. Journal of the Experimental Analysis of Behavior, 7, 383-385.

Weiner, H. (1969). Controlling human fixed-interval performance. Journal of the Experimental Analysis of Behavior, 12, 349-373.

Weiner, H. (1970). Human behavioral persistence. The Psychological Record, 20, 445-456.

Weiner, H. (1983). Some thoughts on discrepant human-animal performances under schedules of reinforcement. The Psychological Record, 33, 521532.

Zeiler, M. D. (1985). The sleeping giant: Reinforcement schedules. Journal of the Experimental Analysis of Behavior, 42, 485-493. 